\title{
BMJ Open Association between the occurrence of albuminuria and the risk of early dementia among older people upon health examination: a community-based cohort study in Taiwan
}

\author{
Tzu-Jung Tseng, ${ }^{1}$ Yun-Ting Yen, ${ }^{1}$ Yuan-Han Yang, ${ }^{2,3,4}$ Yen-Hsu Chen, ${ }^{5,6,7}$ \\ Ta-Chien Chan (iD) ${ }^{1,8}$
}

To cite: Tseng T-J, Yen Y-T, Yang $\mathrm{Y}-\mathrm{H}$, et al. Association between the occurrence of albuminuria and the risk of early dementia among older people upon health examination: a community-based cohort study in Taiwan. BMJ Open 2020;10:e041664. doi:10.1136/ bmjopen-2020-041664

- Prepublication history and additional material for this paper is available online. To view these files, please visit the journal online (http://dx.doi.org/10. 1136/bmjopen-2020-041664)

Received 15 June 2020

Revised 19 November 2020

Accepted 25 November 2020

Check for updates

(c) Author(s) (or their employer(s)) 2020. Re-use permitted under CC BY-NC. No commercial re-use. See rights and permissions. Published by BMJ.

For numbered affiliations see end of article.

Correspondence to

Dr Ta-Chien Chan;

dachianpig@gmail.com

\section{ABSTRACT}

Objectives This study aimed to investigate the associations between biochemical markers, renal function, health behaviours and dementia among older people. Design A retrospective cohort study.

Setting Community-based health examination database from Taipei city.

Participants In total, 35434 older people were included from February 2005 to December 2012. To assess changes in renal function, we selected participants who attended health examinations at least twice and responded to the AD8 questionnaire in 2012. We excluded those with dementia at baseline.

Primary outcome measures Early dementia was assessed using the AD8 questionnaire in 2012.

Explanatory variables included demographic factors, health behaviours, biochemical markers and renal function. We used a Cox proportional hazard model to estimate the HR for early dementia onset.

Results Individuals with mild albuminuria (HR 1.228; 95\% $\mathrm{Cl} 1.066$ to 1.414), lower eGFR (HR 1.549; $95 \% \mathrm{Cl} 1.319$ to 1.820) and higher age (HR 1.022; $95 \% \mathrm{Cl} 1.015$ to 1.028) were associated with a high risk of early dementia. Older people with no alcohol intake (HR 0.872; 95\% Cl 0.794 to 0.958 ), and higher education levels (HR $0.647 ; 95 \% \mathrm{Cl}$ 0.589 to 0.710 ) were at a low risk of early dementia. Conclusions Elevated mild albuminuria and low eGFR were associated with a high risk of early dementia in this community-based cohort. Routine health examinations for older people can help screen out the high-risk population, and clinical management might reduce or delay the risk of early dementia.

\section{INTRODUCTION}

Dementia is characterised by a decline in memory or cognitive functions, thus affecting mental abilities and daily activities. ${ }^{1}$ Dementia is not an aspect of normal ageing, ${ }^{2}$ and it could significantly affect countries with substantial population ageing. Over 9.9 million new dementia cases emerge worldwide annually, with an average of one case every $3.2 \mathrm{~s}^{3}$ In
Strengths and limitations of this study

- This study involved older people from a large community $(n=35434)$, which is more representative than those in previous hospital-based studies.

- Through this cohort, we elucidated the associations between biochemical markers, renal function, health behaviours and dementia (early dementia scale, AD8) from February 2005 to December 2012.

- We could not evaluate changes in AD8 with time or to make causal inferences, because early dementia scores were only evaluated in the final year.

- Only the AD8 score, without a clinical diagnosis, was assessed for early dementia; hence, the results cannot be used to distinguish between Alzheimer disease and vascular dementia.

2015, approximately 47 million individuals had dementia, and this number was predicted to triple by $2050 .{ }^{4}$ In Asia, a meta-analysis reported that the number of individuals with dementia is approaching 8.4 million in China, Hong Kong and Taiwan. ${ }^{5}$ Comprehensive health insurance in Taiwan facilitates robust estimation of dementia prevalence. A nationwide survey from 2011 to 2013 in Taiwan estimated that the age-adjusted dementia prevalence was $8.04 \%$ (0.13 million) among individuals aged $\geq 65$ years. ${ }^{6}$ This prevalence rate in Taiwan is expected to double every 20 years; the number of individuals with dementia will approach 0.32 million by 2030 and exceed 0.6 million by $2050 .^{5}$

Dementia patients need long-term health and social care owing to various disabilities, including financial and social burdens on both the healthcare system and society. The total expenditure for dementia management worldwide was US $\$ 422$ billion in $2009 .^{7}$ In Taiwan, the cost increases with the severity 
of the disease, with mild dementia costing US $\$ 7288$ per year and severe dementia costing US $\$ 14655$ per year. ${ }^{8}$ A continuous tendency to incur such expenses can be expected with an increase in the dementia population. Therefore, dementia has emerged as a significant global challenge in both health and social care in the 21 century. ${ }^{4}$

Previous studies have investigated the cause of dementia to provide better care and for prevention. Alzheimer disease is the most common cause, contributing to $60 \%-80 \%$ of dementia cases. ${ }^{1}$ Another aetiology is vascular dementia, which can occur after a stroke or vascular disease. ${ }^{1}$ Symptoms of vascular disease can be observed in chronic kidney disease (CKD) because blood pressure and water content are not regulated during kidney dysfunction, thus increasing the cardiac output (owing to poor drainage). Similarly, low cardiac contractility reduces blood perfusion and renal function, ${ }^{9}$ resulting in vascular dementia owing to repeated vascular insults caused by CKD. ${ }^{9-11}$ One US study reported that most domains of cognitive function seem to be affected by poor renal function in all stages of CKD due to renal function being damaged by microvascular disorders. ${ }^{12} \mathrm{How}-$ ever, a longitudinal study on new-onset dementia considered renal function but reported no strong association of kidney disease severity and progression with incident dementia. ${ }^{13}$ A previous study among the elderly in China showed that the relative risk of developing cognitive decline was 4.03 among participants with low estimated glomerular filtration rate (eGFR) $(30-59 \mathrm{~mL} /$ $\min / 1.73 \mathrm{~m}^{2}$ ) compared with participants with high eGFR $\left(\geq 60 \mathrm{~mL} / \mathrm{min} / 1.73 \mathrm{~m}^{2}\right)$. Early stage of kidney disease was correlated with cognitive decline. ${ }^{14}$ A study in Japan with subjects aged $\geq 60$ years indicated albuminuria was a risk factor for the development of dementia (both Alzheimer's disease and vascular dementia). Furthermore, albuminuria and low eGFR level were associated with higher risk of vascular dementia. ${ }^{15}$ These studies revealed that kidney function could be correlated with cognitive function in the elderly. Renal function tests can be conveniently performed during routine health examinations, and this is a suitable screening tool for early diagnosis of dementia.

Dementia is a major problem among the elderly. CKD is common among older individuals, and kidney functioning may also decrease with age. We believe that kidney function is a good monitoring indicator of early dementia. Controlling and maintaining kidney function could reduce the risk of dementia and help prevent it through routine health examination. Because previous studies have rarely used data from health examination of older individuals to examine the association between renal function and the early onset of dementia, this study aimed to investigate whether renal function, biochemical markers, and health behaviours are associated with early dementia. ${ }^{16}$

\section{METHOD}

\section{Study design and ethical statement}

This retrospective longitudinal cohort study was based on data obtained from a health examination database of older people. Participants were enrolled and provided written informed consent and to the Taipei City Government to record health examination data for research purposes. Data were curated in the Taipei Geriatric Health Examination Database, and labels were deidentified before release.

Approximately 45000 maximised theoretical capacity of participants registered for this geriatric health examination annually from February 2005 to December 2012. Their participation was voluntary. The AD8 questionnaire was first introduced and used in 2012. Thus, we first selected 40021 older people in 2012 from among 348067 older people from 2005 to 2012 who were undergoing health examination in Taipei City. The endpoint of this study was 2012. Simultaneously, AD8 scores and the results of health examinations were recorded. The remaining baseline risk factors were computed from 2005 to 2012. Although there were 348067 older people from 2005 to 2012 participating in the health examination, we had to select participants who also had health examinations in 2012. Thus, there were 40021 older people included in the first wave of selection. Since our purpose is to evaluate the change from being dementia free to early dementia in these observed years, we excluded individuals with dementia at baseline $(\mathrm{n}=126)$, those with no AD8 scores in $2012(\mathrm{n}=437)$, and those who took the health examination only once $(n=3587)$. Finally, 35434 subjects were enrolled for further assessment (figure 1). Among the original 40021 people, only $8.96 \%$ (3587/40 021) had only one health visit before. The frequency distribution of number of visits in our study population is shown in online supplemental figure 1 .

\section{Cohort description}

This community-based cohort study used data from the Taipei City Elderly Health Examination Database. The study period was February 2005 to December 2012. The Taipei City government provides free annual health examinations for older people in Taipei City. A twostage approach was used to recruit the participants.



Figure 1 Schematic of the enrolment of the study participants. 
In the first stage, aboriginals, those living alone, those living in low-income households, and disabled individuals were recruited through telephone and internet registration at the end of February each year during the study period. In the second stage, all older people registered in Taipei City, who could register for the examination through the telephone, internet or on-site registration in the first week of March each year were recruited. All participants received a health examination once annually. To observe changes in renal function, we only selected participants with at least two visits in this study.

Health examination included a standardised medical examination and a questionnaire addressing several health-related topics. The examination included health history, physical assessment (ie, weight, height, blood pressure, pulse and waist circumference), depression screening, early dementia screening (AD8), biochemistry examination, routine urine examination (urine collected on site), routine blood examination, oral examination and stool examination. The health questionnaire was self-reported, with the prompt assistance of the medical staff if the participants were unable to provide responses. This study used the Mandarin version of the AD8 questionnaire, an early dementia screening scale, in 2012 as the outcome. ${ }^{17}$ Variables included demographic factors and health-related behaviours, such as milk intake, vegetable intake, smoking and alcohol consumption. Furthermore, values of biochemical examination including blood sugar before meals (AC), albumin, serum globulin (GL) and blood urea nitrogen (BUN) were considered.

\section{Patient and public involvement}

This study obtained secondhand data; participants did not receive feedback on the results and were not involved in the study.

\section{AD8 questionnaire}

The health examination data included the AD8 questionnaire-an eight-item questionnaire assessing early dementia. The AD8 questionnaire included yes-or-no questions, and two or more answers of yes were strongly suggestive of dementia. A previous validation study of the AD8 questionnaire conducted among Taiwanese individuals revealed a sensitivity of $97.6 \%$ and a specificity of $78.1 \% .{ }^{17}$ The questionnaire includes memory, orientation, executive functioning, and interest in activities. Furthermore, the questionnaire items included difficulties in judgement, reduced interest in activities and hobbies, repeating the same problem or story statement, difficulties in learning to use tools and equipment, forgetting the year and month, finding it challenging to deal with complicated finances, and failing to remember appointment times. Eight questions were listed to investigate continuous thinking and memory issues.
Demographic variables, health behaviours and biochemical data

We used a self-reported questionnaire including demographic characteristics, health behaviours, and biochemical results. Demographic characteristics such as age, sex, body mass index (BMI) (classified into four levels: BMI $<18.5 \mathrm{~kg} / \mathrm{m}^{2}, 18.5 \leq \mathrm{BMI}<24 \mathrm{~kg} / \mathrm{m}^{2}, 24 \leq \mathrm{BMI}<27 \mathrm{~kg} /$ $\mathrm{m}^{2}$ and BMI $\geq 27 \mathrm{~kg} / \mathrm{m}^{2}$ ), educational level (categorised into three levels: university and above, senior and junior high school, and primary level and below) were collected. Health behaviours including long-term medication (yes or no), exercise (yes or no) and substance usage (alcohol drinker or non-drinker and smoker or non-smoker) were gathered. Individual health information including longterm medication use and physical and biochemical values (ie, BMI, albuminuria ('-', negative, $<10 \mathrm{mg} / \mathrm{dL}$; ' \pm ', trace, $10-20 \mathrm{mg} / \mathrm{dL}$; '+', 21-30 mg/dL; '++', 31-100 mg/ $\mathrm{dL}$; '+++', 101-300 mg/dL: '++++', $\geq 301 \mathrm{mg} / \mathrm{dL})$, eGFR $\left(\mathrm{mL} / \mathrm{min} / 1.73 \mathrm{~m}^{2}\right)$, BUN $(\mathrm{mg} / \mathrm{dL})$, albumin $(\mathrm{mg} / \mathrm{dL})$, $\mathrm{AC}(\mathrm{mg} / \mathrm{dL})$ and globulin $(\mathrm{mg} / \mathrm{dL}))$ were obtained. The eGFR was determined as follows ${ }^{18}$ :

$$
\begin{gathered}
186 \times \text { Serum creatinine }{ }^{-1.154} \times \text { Age }^{-0.203} \\
\text { Male } \times 1 ; \text { Female } \times 0.742
\end{gathered}
$$

Independent variables included continuous variables such as age, BMI, AC, GL and BUN and categorical binary variables (yes or no) including smoking, alcohol consumption, and long-term medication use. Other categorical variables, such as groups of eGFR, albuminuria, education level and sex, were also assessed.

\section{Statistical analyses}

To determine the risk factors that were significantly associated with early dementia, survival analysis with a Cox proportional hazard model was performed. The changes over time in the different levels of eGFR or albuminuria levels of early dementia are presented in the survival plot. We adjusted age and gender in the analysis. A Cox proportional hazard model helped evaluate the probability of early dementia in 2012. The starting time was set at the time of the first health examination date. We simultaneously obtained baseline information, and the data were censored in the last health examination for each participant. The average follow-up duration was 5.05 years.

We determined the occurrence of early dementia from the censoring time. All $\mathrm{p}$ values were two tailed, and $\mathrm{p}<0.05$ was considered significant. Statistical analyses were performed using SPSS V.25.0 (IBM).

\section{RESULTS}

\section{Study population}

Tables 1 and 2 display the descriptive statistics of categorical and continuous variables. The AD8 score was divided into two categories (a score of $<2$ was considered normal, whereas a score of $\geq 2$ was indicative of early dementia) on the basis of previous results. ${ }^{17}$ In the Taipei City health 
Table 1 Characteristics of older people enrolled in the present study

\begin{tabular}{|c|c|c|c|}
\hline Variables & & $\mathbf{N}$ & $\%$ \\
\hline \multirow[t]{2}{*}{ AD8 score } & $<2$ & 31208 & 88.1 \\
\hline & $\geq 2$ & 4226 & 11.9 \\
\hline \multirow[t]{5}{*}{ BMI } & $\mathrm{BMI}<18.5$ & 1182 & 3.3 \\
\hline & $18.5 \leq \mathrm{BMl}<24$ & 15441 & 43.6 \\
\hline & $24 \leq \mathrm{BMl}<27$ & 10534 & 29.7 \\
\hline & $\mathrm{BMI} \geq 27$ & 5821 & 16.4 \\
\hline & Missing & 2456 & 6.9 \\
\hline \multirow[t]{5}{*}{ eGFR } & $>75$ & 16141 & 45.6 \\
\hline & $60-75$ & 8819 & 24.9 \\
\hline & $45-59$ & 5308 & 15.0 \\
\hline & $<45$ & 1545 & 4.4 \\
\hline & missing & 3621 & 10.2 \\
\hline \multirow[t]{3}{*}{ Long-term medication } & Yes & 23972 & 67.7 \\
\hline & No & 9232 & 26.1 \\
\hline & Missing & 2230 & 6.3 \\
\hline \multirow[t]{4}{*}{ Albuminuria } &,- \pm & 30314 & 85.3 \\
\hline &,+++ & 1812 & 5.1 \\
\hline &,+++++++ & 149 & 0.4 \\
\hline & Missing & 3259 & 9.2 \\
\hline \multirow[t]{3}{*}{ Alcohol intake } & Yes & 6166 & 17.4 \\
\hline & No & 26979 & 76.1 \\
\hline & Missing & 2289 & 6.5 \\
\hline \multirow[t]{3}{*}{ Smoking status } & Yes & 2004 & 5.7 \\
\hline & No & 30680 & 86.6 \\
\hline & Missing & 2750 & 7.8 \\
\hline \multirow[t]{4}{*}{ Education } & University and above & 11275 & 31.8 \\
\hline & Senior and junior high & 12788 & 36.1 \\
\hline & primary and below & 9141 & 25.8 \\
\hline & Missing & 2230 & 6.3 \\
\hline \multirow[t]{3}{*}{ Gender } & Male & 16897 & 47.7 \\
\hline & Female & 16307 & 46.0 \\
\hline & Missing & 2230 & 6.3 \\
\hline
\end{tabular}

Data are presented as numbers $(\mathrm{N})$ and percentages (\%). BMI, body mass index.

examination data, $88.1 \%$ of the older people received scores of $<2$, whereas $11.9 \%$ had scores of $\geq 2$. Most participants were using long-term medication $(67.7 \%)$, did not consume alcohol $(76.1 \%)$, were nonsmokers $(86.6 \%)$, were male $(47.7 \%)$, had at least a junior high school education level $(67.9 \%)$, and had normal albuminuria $(85.3 \%)$.

The outcomes of physical and biochemical examination for the study population are summarised in table 2. All average biochemical values were within normal reference levels, including AC $(103.88 \mathrm{mg} / \mathrm{dL}, \mathrm{SD}=23.42)$, serum albumin $(4.37 \mathrm{mg} / \mathrm{dL}, \mathrm{SD}=0.69)$, GL $(3.02 \mathrm{mg} / \mathrm{dL}$,
$\mathrm{SD}=0.86)$, BUN $(16.3 \mathrm{mg} / \mathrm{dL}, \mathrm{SD}=6.01)$, age $(71.07$ years, $\mathrm{SD}=5.63)$ and $\mathrm{BMI}(23.97, \mathrm{SD}=3.33)$.

\section{$\chi^{2}$ analysis}

A $\chi^{2}$ test was performed separately for each independent variable to assess the associations of an $\mathrm{AD} 8$ score of $<2$ with the personal characteristics in table 3 . Albuminuria, eGFR class, education level, sex and alcohol consumption differed significantly between the group with AD8 scores of $<2$ and the group with AD8 scores of $\geq 2$.

\section{Survival analysis}

The risk and protective factors associated with AD8 were further examined through survival analysis (table 4). The survival function at mean of covariates in online supplemental figure 2 showed the probability of survival decreased with the time changes. In online supplemental figure 3 , we depicted the cumulative hazard function to evaluate all covariates of their mean values. As shown in online supplemental figure 3 , this hazard function peaks over time. Thus, the risk of event occurrence increases over time. The survival curves in the appendix (see online supplemental figures 4-6) show the difference between different groups of albuminuria and different levels of eGFR. The hazard of this study population with different eGFR or albuminuria levels changed with time. Compared with normal albuminuria, individuals with albuminuria + and ++ had a higher HR 1.228, 95\% CI 1.066 to 1.414. Higher eGFR was associated with lower HR (eGFR $<45 \mathrm{~mL} / \mathrm{min} / 1.73 \quad \mathrm{~m}^{2}, \quad \mathrm{HR}=1.549 ; \quad$ eGFR $=45-59 \mathrm{~mL} /$ $\min / 1.73 \mathrm{~m}^{2}, \mathrm{HR}=1.244 ;$ eGFR $=60-74 \mathrm{~mL} / \mathrm{min} / 1.73 \mathrm{~m}^{2}$, $\mathrm{HR}=1.149 ; \mathrm{p}=0.004$ ). Therefore, a high eGFR may be associated with a high risk of early dementia. Regarding education levels, individuals with a senior or junior high degree (HR $=0.776,95 \%$ CI 0.715 to 0.842 ) and those with a university or higher degree (HR $=0.647,95 \%$ CI 0.589 to 0.710 ) had lower HRs than those with an education level of primary school or below. Regarding health behaviour, non-drinkers $(\mathrm{HR}=0.872,95 \%$ CI 0.794 to 0.958$)$ had a lower HR than drinkers did. Regarding age, older people had a higher HR (HR=1.022, 95\% CI 1.015 to 1.028$)$ than younger individuals did.

\section{DISCUSSION}

This study of 35434 older people indicated that high albuminuria and low eGFR levels are associated with a high risk of early dementia. This finding is consistent with those of previous studies reporting that albuminuria is associated with worse cognitive function. ${ }^{19}{ }^{20}$ Moreover, moderate albuminuria, but not severe albuminuria, was significantly associated with early dementia. Low eGFR was also significantly associated with early dementia. Previous studies investigating the association between eGFR and cognitive function have presented inconsistent results. ${ }^{2122}$

Although some cross-sectional studies have reported that low eGFR is associated with cognitive impairment, ${ }^{1123}$ 
Table 2 Outcomes of physical and biochemical assessments of the study population

\begin{tabular}{lcccrrrr}
\hline & N & Minimal & Maximum & Mean & Medium & SD & IQR \\
\hline Glucose & 35091 & 1.06 & 331.00 & 103.88 & 98 & 23.42 & 17.0 \\
Serum albumin & 34721 & 0.500 & 47.10 & 4.37 & 4.40 & 0.69 & 0.30 \\
Globulin & 34688 & 0.800 & 132.00 & 3.02 & 3.00 & 0.86 & 0.50 \\
Blood urea nitrogen & 34715 & 0.660 & 224.00 & 17.21 & 16.30 & 6.01 & 5.40 \\
Age & 33,204 & 65.00 & 100.00 & 71.07 & 70 & 5.63 & 9.0 \\
BMl & 33204 & 10.58 & 43.28 & 24.13 & 23.97 & 3.33 & 4.17 \\
serum creatinine & 35108 & 0 & 241 & 1 & 0.9 & 1.37 & 0.3 \\
eGFR & 32889 & 0.14 & 1256 & 74.91 & NA & 23.22 & 24.6 \\
Average follow-up time (days) & 35434 & 108 & 2766 & 1845 & NA & 726.73 & 1145 \\
\hline
\end{tabular}

Data are presented as numbers $(\mathrm{N})$.

BMI, body mass index; NA, not available.

the results have been inconsistent among older males. ${ }^{24}$ Rigorous testing and monitoring of kidney function and a comprehensive evaluation of dementia would be practical solutions in future assessments to better understand this association. The biological mechanisms, in addition to vascular contributions, ${ }^{25}$ among albuminuria, eGFR and dementia, require further study.

A previous meta-analysis involving 32 eligible studies reported that albuminuria is independently associated with cognitive impairment, dementia and cognitive decline and that vascular dementia and cognitive performance were primarily affected by microvascular disease. ${ }^{26}$ Therefore, microvascular disease mediates the association between poor renal function and dementia. Another meta-analysis reported that albuminuria is associated with a higher risk of cognitive impairment or dementia. However, the association between renal dysfunction and cognitive impairment or dementia was modest. ${ }^{27}$ We obtained data from older people aged $\geq 65$ years. These results indicate that high albuminuria and low eGFR are associated with a higher risk of cognitive disorders and early dementia, concurrent with the aforementioned reports. Furthermore, eGFR had a dose-response association with early dementia; the lower the eGFR, the higher the HR.

\begin{tabular}{|c|c|c|c|c|c|c|c|}
\hline & & \multicolumn{2}{|l|}{ AD8 $<2$} & \multicolumn{2}{|c|}{ AD8 $\geq 2$} & \multirow[t]{2}{*}{$P$ value } & \multirow[t]{2}{*}{$\mathrm{x}^{2}$} \\
\hline & & $\mathbf{N}$ & $\%$ & $\mathbf{N}$ & $\%$ & & \\
\hline \multirow[t]{3}{*}{ Albuminuria } &,- \pm & 26653 & 94.0 & 3561 & 92.9 & 0.02 & 7.818 \\
\hline &,+++ & 1599 & 5.5 & 253 & 6.6 & & \\
\hline &,+++++++ & 130 & 0.5 & 19 & 0.5 & & \\
\hline \multirow[t]{2}{*}{ Long-term medication } & No & 8189 & 27.9 & 1043 & 27.3 & 0.450 & 0.570 \\
\hline & Yes & 21193 & 72.1 & 2779 & 72.7 & & \\
\hline \multirow[t]{4}{*}{ eGFR } & $>75$ & 14339 & 50.9 & 1802 & 49.3 & 0.031 & 4.686 \\
\hline & $60-74$ & 7799 & 27.7 & 1020 & 27.9 & & \\
\hline & $45-59$ & 4667 & 16.6 & 641 & 17.5 & & \\
\hline & $<45$ & 1354 & 4.8 & 191 & 5.2 & & \\
\hline \multirow[t]{2}{*}{ Smokes or not } & No & 27136 & 93.8 & 3544 & 94.0 & 0.66 & 0.194 \\
\hline & Yes & 1779 & 6.2 & 225 & 6.0 & & \\
\hline \multirow[t]{3}{*}{ Education } & Primary or less & 7850 & 26.7 & 1291 & 33.8 & $<0.0001$ & 124.358 \\
\hline & Senior and junior high & 11287 & 38.4 & 1501 & 39.3 & & \\
\hline & University and above & 10245 & 34.9 & 1030 & 26.9 & & \\
\hline \multirow[t]{2}{*}{ Gender } & Female & 14308 & 48.7 & 1999 & 52.3 & $<0.0001$ & 17.596 \\
\hline & Male & 15074 & 51.3 & 1823 & 47.7 & & \\
\hline \multirow[t]{2}{*}{ Alcohol intake } & No & 23832 & 81.3 & 3147 & 82.4 & 0.083 & 3.014 \\
\hline & Yes & 5495 & 18.7 & 671 & 17.6 & & \\
\hline
\end{tabular}




\begin{tabular}{|c|c|c|c|c|}
\hline & B & $\mathbf{P}$ & HR & $95 \% \mathrm{Cl}$ \\
\hline $60-74$ vs $\geq 75$ & 0.139 & $0.013^{\star}$ & 1.149 & 1.030 to 1.282 \\
\hline$<45$ vs $\geq 75$ & 0.438 & $<0.001 \ddagger$ & 1.549 & 1.319 to 1.820 \\
\hline Continuous & -0.002 & $0.004 \uparrow$ & 0.998 & 0.996 to 0.999 \\
\hline,+++++++ vs,- \pm & 0.069 & 0.796 & 1.072 & 1.072 to 0.634 \\
\hline No versus yes & -0.137 & $0.004^{*}$ & 0.872 & 0.794 to 0.958 \\
\hline No versus yes & -0.065 & 0.097 & 0.937 & 0.867 to 1.012 \\
\hline No versusvs yes & 0.095 & 0.203 & 1.100 & 0.950 to 1.274 \\
\hline Male versus female & -0.009 & 0.890 & 0.991 & 0.866 to 1.133 \\
\hline $24 \leq \mathrm{BMI}<27$ vs $\mathrm{BMI}<18.5$ & 0.055 & 0.570 & 1.056 & 0.875 to 1.275 \\
\hline $\mathrm{BMI} \geq 27$ vs $\mathrm{BMI}<18.5$ & 0.019 & 0.849 & 1.019 & 0.837 to 1.275 \\
\hline & 0.021 & $<0.001 \ddagger$ & 1.022 & 1.015 to 1.028 \\
\hline & -0.002 & 0.939 & 0.998 & 0.954 to 1.044 \\
\hline & -0.001 & 0.272 & 0.999 & 0.998 to 1.001 \\
\hline & 0.002 & 0.479 & 1.002 & 0.998 to 1.008 \\
\hline & 0.003 & 0.905 & 1.003 & 0.960 to 1.047 \\
\hline
\end{tabular}

${ }^{*} p<0.05$.

$\dagger p<0.01$.

$\neq \mathrm{p}<0.001$.

AC, blood sugar before meals; Alb, albumin; BMI, body mass index; BUN, blood urea nitrogen; GL, serum globulin.

Sex and age were previously considered the most prominent dementia risk factors ${ }^{28}$; female sex is a risk factor for mild cognitive impairment. ${ }^{29-31}$ Our results are partially consistent with those of previous studies reporting that a higher age is significantly associated with early dementia; however, sex was not a significant factor in the present study. Weight loss with age is assumed to negatively impact the brain. ${ }^{32}$ Decreased weight and cognitive impairment result in progressive degeneration ${ }^{33}$ and may potentially accelerate brain damage, potentially owing to poor nutrition, chronic disease and lack of physical activity. BMI was not significantly associated with potential early dementia. Furthermore, alcohol consumption was associated with an increased risk of early dementia. One study reported that alcohol consumption of $\leq 2$ units/day (one unit is defined as a beverage containing approximately $20 \mathrm{~g}$ alcohol) could reduce the risk of dementia among older Japanese adults. ${ }^{34}$ However, a previous review reported a dose-response effect of alcohol consumption on the deterioration of cognitive function. Frequent heavy alcohol consumption may damage brain function and decrease cognitive functions, whereas light to moderate alcohol consumption has protective effects. ${ }^{35}$ This study did not report a dose-response effect because the questionnaire simply provided information regarding whether alcohol consumption had an effect. Podcasy and Epperson emphasised behavioural interventions including diet and exercise for both sexes to achieve beneficial effects. ${ }^{28}$ Thus, policy-makers should develop preventative programmes for both sexes.

Furthermore, education levels higher than primary school were found to have a protective effect against dementia, which was consistent with a previous study reporting that lower education levels are associated with a higher dementia risk. ${ }^{36}$ Further studies are required to investigate the risk factors of dementia, including life experiences, professional achievements and leisure activities, which are associated with cognitive reserve theory. ${ }^{37}$

This study has some limitations. First, early dementia scores were available only for the final year; therefore, we could not evaluate changes over time or make causal inferences. We only considered the baseline (data from first visit) and endpoint (data from the last visit) in the Cox proportional model to evaluate the association between risk factors and the risk of early dementia instead of including time dependence in the Cox proportional model. Moreover, we may not know the health status of participants who did not attend in 2012. They may not have been able to participate in the health examination annually due to poor health status or progression to 
dementia, which may cause our results to be underestimated. It is possible that residents in care homes were able to participate in this health examination, while they may have had low willingness to participate due to their poor health status or disability. However, we may not be able to distinguish them from our data. Furthermore, the study subjects included older people from Taipei City receiving health examinations; these individuals tend to care more about health than those who did not participate, thus limiting the generalisability of our findings to other populations. A previous study reported that the mortality in this cohort was similar to the nationwide mortality $(0.62 \%$ vs $0.67 \%),{ }^{38}$ implying that our study population may have reliable generalisability. Furthermore, only the AD8 score was assessed for early dementia, without diagnosis. Herein, $11.9 \%$ of older individuals may have early dementia, whereas the prevalence of dementia among individuals aged $\geq 65$ years in Taiwan was $8.04 \%$ in $2013 .{ }^{6}$ The differences in these prevalence rates might occur due to the different study designs. In addition, our study did not collect physical and neurological examinations, interviews of the families and attending physicians or medical records to diagnose dementia. Further clinical diagnosis would help to screen individuals with cognitive impairment and improve estimation. In addition, we did not distinguish between Alzheimer disease and vascular dementia. Based on a previous study by Yang et $a l^{17}$, the AD8 questionnaire is a good tool with high sensitivity $(97.6 \%)$ to detect early dementia, and it was highly correlated with the sum of the boxes of an clinical dementia rating scale $(\mathrm{r}=0.834, \mathrm{p}<0.0001)$. The cut-off value of AD8 set at two can discriminate between normal participants and those with mild dementia. In order to increase accuracy, clinical diagnosis is needed. Moreover, we excluded those with self-reported dementia at the beginning. However, those who were not excluded may also have had dementia but been unaware of it. Finally, the underestimation of health behaviours from self-reported questionnaires could have been affected by the socially desirable expectations. However, no further objective data were available to verify the accuracy of the self-reported health behaviours.

Nonetheless, this study had several strengths. The present cohort comprised older individuals in Taipei, Taiwan, who had undergone a comprehensive health examination at least twice. Furthermore, this study population comprised older individuals from the community rather than hospitalised patients; thus, the population was more representative than those of previous studies. ${ }^{39}$ This community database provides fruitful information regarding early dementia and potential prevention strategies.

In conclusion, among the older individuals in the present study, elevated mild albuminuria, low eGFR and alcohol consumption were associated with early dementia. Advocating community health examinations would help identify groups with a high risk of early dementia.

\section{Author affiliations}

${ }^{1}$ Research Center for Humanities and Social Sciences, Academia Sinica, Taipei, Taiwan

${ }^{2}$ Department of Neurology, Kaohsiung Medical University, Kaohsiung, Taiwan

${ }^{3}$ Department of Neurology, Kaohsiung Municipal Ta-Tung Hospital, Kaohsiung, Taiwan

${ }^{4}$ Neuroscience Research Center, Kaohsiung Medical University, Kaohsiung, Taiwan ${ }^{5}$ Department of Internal Medicine, Kaohsiung Municipal Ta-Tung Hospital, Kaohsiung, Taiwan

${ }^{6}$ School of Medicine, Graduate Institute of Medicine, Sepsis Research Center, Center of Tropical Medicine and Infectious Diseases, Kaohsiung Medical University, Kaohsiung, Taiwan

${ }^{7}$ Department of Biological Science and Technology, College of Biological Science and Technology, National Chiao Tung University, Hsinchu, Taiwan

${ }^{8}$ Institute of Public Health, School of Medicine, National Yang-Ming University, Taipei, Taiwan

Acknowledgements We thank the Department of Health, Taipei City Government for allowing the use of data for this research and all of participants.

Contributors T-JT, Y-TY and Y-HY reviewed the literature and made substantial contributions to the conception and design. T-JT and Y-TY refined the data and performed statistical analysis. Y-HY and Y-HC interpreted the results. Y-HY and T-CC conceptualised and designed the paper, interpreted the results and drafted the manuscript. All authors have read and approved the final manuscript.

Funding This research was supported by a grant from the Ministry of Science and Technology, Taiwan (MOST-106-2627-M-001-003) and a grant titled 'Multidisciplinary Health Cloud Research Program: Technology Development and Application of Big Health Data' from Academia Sinica.

Disclaimer The funders had no role in the study design, data collection and analysis, decision to publish, or preparation of the manuscript.

Competing interests None declared.

Patient consent for publication Not required.

Ethics approval The study was approved by the Institutional Review Board (IRB) on Biomedical Science Research, Academia Sinica (AS-IRB02-104182).

Provenance and peer review Not commissioned; externally peer reviewed.

Data availability statement Data may be obtained from a third party and are not publicly available. The raw data are confidential and cannot be readily shared. Researchers must obtain permission from the IRB and apply for access to the data from the Department of Health, Taipei City Government.

Supplemental material This content has been supplied by the author(s). It has not been vetted by BMJ Publishing Group Limited (BMJ) and may not have been peer-reviewed. Any opinions or recommendations discussed are solely those of the author(s) and are not endorsed by BMJ. BMJ disclaims all liability and responsibility arising from any reliance placed on the content. Where the content includes any translated material, BMJ does not warrant the accuracy and reliability of the translations (including but not limited to local regulations, clinical guidelines, terminology, drug names and drug dosages), and is not responsible for any error and/or omissions arising from translation and adaptation or otherwise.

Open access This is an open access article distributed in accordance with the Creative Commons Attribution Non Commercial (CC BY-NC 4.0) license, which permits others to distribute, remix, adapt, build upon this work non-commercially, and license their derivative works on different terms, provided the original work is properly cited, appropriate credit is given, any changes made indicated, and the use is non-commercial. See: http://creativecommons.org/licenses/by-nc/4.0/.

ORCID iD

Ta-Chien Chan http://orcid.org/0000-0002-1685-783X

\section{REFERENCES}

1 Alzheimer's association. What is dementia? 2019. Available: https:// www.alz.org/alzheimers-dementia/what-is-dementia

2 The World Health Organization. 10 facts on dementia, 2017. Available: https://www.who.int/features/factfiles/dementia/en/

3 The global voice on dementia. World Alzheimer report 2015 reveals global cost of dementia set to reach US \$1 trillion by 2018, 2015. 
Available: https://www.alz.co.uk/news/world-alzheimer-report2015-reveals-global-cost-of-dementia-set-to-reach-usd-1-trillionby-2018

4 Livingston G, Sommerlad A, Orgeta V, et al. Dementia prevention, intervention, and care. Lancet 2017;390:2673-734.

$5 \mathrm{Wu}$ Y-T, Lee H-Y, Norton S, et al. Prevalence studies of dementia in mainland China, Hong Kong and Taiwan: a systematic review and meta-analysis. PLoS One 2013;8:e66252.

6 Sun Y, Lee H-J, Yang S-C, et al. A nationwide survey of mild cognitive impairment and dementia, including very mild dementia, in Taiwan. PLoS One 2014;9:e100303.

7 Wimo A, Winblad B, Jönsson L. An estimate of the total worldwide societal costs of dementia in 2005. Alzheimers Dement 2007;3:81-91.

$8 \mathrm{Ku}$ L-JE, Pai M-C, Shih P-Y. Economic impact of dementia by disease severity: exploring the relationship between stage of dementia and cost of care in Taiwan. PLoS One 2016;11:e0148779.

9 Weiner DE. The cognition-kidney disease connection: lessons from population-based studies in the United States. Am J Kidney Dis 2008;52:201-4.

10 Elias MF, Elias PK, Seliger SL, et al. Creatinine and cognitive functioning. Nephrol Dial Transplant 2009;24:2446-52.

11 Tsai C-F, Wang S-J, Fuh J-L. Moderate chronic kidney disease is associated with reduced cognitive performance in midlife women. Kidney Int 2010;78:605-10.

12 Zammit AR, Katz MJ, Bitzer M, et al. Cognitive impairment and dementia in older adults with chronic kidney disease: a review. Alzheimer Dis Assoc Disord 2016;30:357-66.

13 O'Hare AM, Walker R, Haneuse S, et al. Relationship between longitudinal measures of renal function and onset of dementia in a community cohort of older adults. J Am Geriatr Soc 2012;60:2215-22.

14 Bai K, Pan Y, Lu F, et al. Kidney function and cognitive decline in an oldest-old Chinese population. Clin Interv Aging 2017;12:1049-54.

15 Takae K, Hata J, Ohara T, et al. Albuminuria increases the risks for both Alzheimer disease and vascular dementia in communitydwelling Japanese elderly: the Hisayama study. J Am Heart Assoc 2018;7. doi:10.1161/JAHA.117.006693. [Epub ahead of print: 2001 2018].

16 Inker LA, Astor BC, Fox CH, et al. KDOQI us commentary on the 2012 KDIGO clinical practice guideline for the evaluation and management of CKD. Am J Kidney Dis 2014;63:713-35.

17 Yang Y-H, Galvin JE, Morris JC, et al. Application of AD8 questionnaire to screen very mild dementia in Taiwanese. Am J Alzheimers Dis Other Demen 2011;26:134-8.

18 Schwartz GJ, Work DF. Measurement and estimation of GFR in children and adolescents. Clin J Am Soc Nephrol 2009;4:1832-43.

19 Weiner DE, Bartolomei K, Scott T, et al. Albuminuria, cognitive functioning, and white matter hyperintensities in homebound elders. Am J Kidney Dis 2009:53:438-47.

$20 \mathrm{Kuo} \mathrm{H-K}$, Lin L-Y, Yu Y-H. Microalbuminuria is a negative correlate for cognitive function in older adults with peripheral arterial disease: results from the U.S. National health and nutrition examination survey 1999-2002. J Intern Med 2007;262:562-70.
21 Joosten H, Izaks GJ, Slaets JPJ, et al. Association of cognitive function with albuminuria and eGFR in the general population. Clin $\mathrm{J}$ Am Soc Nephrol 2011;6:1400-9.

22 Buchman AS, Tanne D, Boyle PA, et al. Kidney function is associated with the rate of cognitive decline in the elderly. Neurology 2009;73:920-7.

23 Yaffe K, Ackerson L, Kurella Tamura M, et al. Chronic kidney disease and cognitive function in older adults: findings from the chronic renal insufficiency cohort cognitive study. J Am Geriatr Soc 2010;58:338-45.

24 Slinin Y, Paudel ML, Ishani A, et al. Kidney function and cognitive performance and decline in older men. J Am Geriatr Soc 2008;56:2082-8.

25 Yang Y, Fuh J, Mok VCT. Vascular contribution to cognition in stroke and Alzheimer's disease. Brain Science Advances 2018;4:39-48.

26 Georgakis MK, Dimitriou NG, Karalexi MA, et al. Albuminuria in association with cognitive function and dementia: a systematic review and meta-analysis. J Am Geriatr Soc 2017;65:1190-8.

27 Deckers K, Camerino I, van Boxtel MPJ, et al. Dementia risk in renal dysfunction: a systematic review and meta-analysis of prospective studies. Neurology 2017;88:198-208.

28 Podcasy JL, Epperson CN. Considering sex and gender in Alzheimer disease and other dementias. Dialogues Clin Neurosci 2016;18:437-46.

29 Bell SP, Liu D, Samuels LR, et al. Late-life body mass index, rapid weight loss, apolipoprotein E $\varepsilon 4$ and the risk of cognitive decline and incident dementia. J Nutr Health Aging 2017;21:1259-67.

30 Park KM, Sung JM, Kim WJ, et al. Population-based dementia prediction model using Korean public health examination data: a cohort study. PLoS One 2019;14:e0211957.

31 Ronquillo JG, Baer MR, Lester WT. Sex-specific patterns and differences in dementia and Alzheimer's disease using informatics approaches. J Women Aging 2016;28:403-11.

32 Field AE, Malspeis S, Willett WC. Weight cycling and mortality among middle-aged or older women. Arch Intern Med 2009;169:881-6.

33 Vupputuri S, Shoham DA, Hogan SL, et al. Microalbuminuria, peripheral artery disease, and cognitive function. Kidney Int 2008;73:341-6.

34 Liu Y, Mitsuhashi T, Yamakawa M, et al. Alcohol consumption and incident dementia in older Japanese adults: the Okayama study. Geriatr Gerontol Int 2019;19:740-6.

35 Gutwinski S, Schreiter S, Priller J, et al. Drink and think: impact of alcohol on cognitive functions and dementia - evidence of doserelated effects. Pharmacopsychiatry 2018;51:136-43.

36 Brayne C, Ince PG, et al. Education, the brain and dementia: neuroprotection or compensation? Brain 2010;133:2210-6.

37 Sharp ES, Gatz M. Relationship between education and dementia: an updated systematic review. Alzheimer Dis Assoc Disord 2011;25:289-304.

38 Chung P-C, Chan T-C. Association between periodontitis and allcause and cancer mortality: retrospective elderly community cohort study. BMC Oral Health 2020;20:168.

39 Wang $F$, Zhang L, Liu L, et al. Level of kidney function correlates with cognitive decline. Am J Nephrol 2010;32:117-21. 